\title{
Potencialidade de utilização da ilha do Terrapleno de Leste para a disposição de sedimentos dragados no porto de Rio Grande, Brasil
}

\author{
Bernardo VILLWOCK', João Luiz NICOLODI² \& Lauro Júlio CALLIARI² \\ 1 Programa de Pós Graduação em Gerenciamento Costeiro, Instituto de Oceanografia, Universidade \\ Federal do Rio Grande. Av. Itália, Km 08, CEP 96203-900, Rio Grande, RS, Brasil \\ (bernardovillwock@hotmail.com). \\ ${ }^{2}$ Laboratório de Oceanografia Geológica, Instituto de Oceanografia, Universidade Federal do Rio Grande. \\ Av. Itália, Km 08, CEP 96203-900, Rio Grande, RS, Brasil (joaonicolodi@furg.br; Icalliari@log.furg.br).
}

\begin{abstract}
Resumo. $O$ descarte de sedimentos dragados em portos e hidrovias é uma das questões mais críticas para o gerenciamento de portos costeiros. O descarte em mar aberto continua sendo uma das alternativas mais amplamente utilizadas no Brasil, embora possa gerar impactos ambientais significativos. O descarte em terra tem sido utilizado em várias partes do mundo, pois, quando feito corretamente, fornece um uso benéfico para esses sedimentos. Com base no histórico da atividade de dragagem no Porto de Rio Grande/RS, em análises sedimentológicas, em estudos sobre variações na linha de costa e em estimativas de volumes de sedimentos foi definido um uso alternativo para os produtos de dragagem. Os resultados obtidos apontam a Ilha Terrapleno de Leste como uma área prioritária para o local de disposição. O descarte de sedimentos nesta ilha reduziria a quantidade de sedimentos finos lançados no oceano e contribuiria para a estabilização de sua margem leste, que possui taxas de erosão de 1 metro/ ano. Além disso, os sedimentos amostrados na ilha são compatíveis com o material dragado, sendo que o volume estimado para deposição na ilha seria da ordem de 3,9 milhões de $m$ cúbicos.
\end{abstract}

Palavras-chave. Dragagem de Portos; Gestão de Sedimentos; Porto de Rio Grande.

\begin{abstract}
POTENTIAL USE OF THE TERRAPLENO DE LESTE ISLAND FOR A DISPOSAL OF DREDGED SEDIMENTS IN THE PORT OF RIO GRANDE, BRAZIL. The disposal of dredged sediments in ports and waterways is one of the most critical issues for coastal port management. Open ocean disposal remains one of the most widely used alternatives in Brazil, even though it can generate significant environmental impacts. Land-based disposal has been used in various parts of the world since when done properly it provides a beneficial use for these sediments. Based on the history of dredging activity at the Port of Rio Grande/RS, on sedimentological analysis, coastline variations and estimates of sediment volumes, an alternative use for dredging products was defined. The results obtained point to the Terrapleno de Leste Island as a priority area for the disposal site. The disposal of sediments on this island would reduce the amount of fine sediments released into the ocean and contribute to the stabilization of its eastern shore, which has erosion rates of 1 meter/year. In addition, the sediments sampled on the island are compatible with the dredged material, and the estimated volume for deposition on the island would be in the order of 3.9 million cubic $m$.
\end{abstract}

Keywords. Dredging of Ports; Sediment Management; Port of Rio Grande. 


\section{Introdução}

A dragagem é o processo de realocação de sedimentos e solos para fins de construção e manutenção de vias aquáticas, de infraestrutura de transporte, de aterros e de recuperação de solos ou de mineração (CONAMA, 2012). Desde as primeiras dragagens até a atualidade, seus resíduos foram dispostos de forma aleatória, em locais onde, muitas vezes, impactavam significativamente o meio ambiente, sem maiores questionamentos a respeito desse aspecto (Goes Filho, 1979, 2004).

A preocupação com a gestão adequada do material dragado só passou a ser discutida com maior ênfase a partir das últimas décadas. Configurando essa tendência, a Conferência de Estocolmo, realizada em 1972, deu origem às regulamentações internacionais de depósito dos materiais dragados em áreas marítimas (Vellinga, 1998). Tal fato decorre, sobretudo, do desenvolvimento de uma conscientização ambiental, que terminou por direcionar a atenção das autoridades e da sociedade para os inconvenientes da disposição inadequada dos resíduos de dragagem (Castro \& Almeida, 2012). Esta situação aponta para a necessidade de estudos específicos para a disposição destes materiais, bem como para o seu tratamento, quando indispensável. Com isso, a disposição dos sedimentos dragados vem deixando de ser "livre", provocando um aumento nos custos e na complexidade das operações. Estudos e pesquisas passaram a serem exigidos para a definição dos processos químicos, físicos, geológicos e biológicos referentes ao material dragado e sua interação com o meio ambiente (Lima, 2008). Novas técnicas de disposição e tratamento foram criadas, bem como, algumas técnicas, antes inviáveis, tornaram-se viáveis. No desenvolvimento deste processo, também ocorreu uma profunda alteração na forma de aproveitamento do material dragado, que deixou de ser considerado um simples resíduo a ser eliminado, tornando-se um recurso natural importante e passível de aproveitamentos múltiplos (Goes Filho, 2004; Lima, 2008).

Várias centenas de milhões de $\mathrm{m}^{3}$ de sedimentos são dragados anualmente no mundo, porém não há consenso sobre a forma mais adequada de gerir esse material. Define-se o produto da dragagem como um recurso natural valioso quando aplicado em usos benéficos para o homem (PIANC, 1992). Na maioria dos países em desenvolvimento, entretanto, este material é visto como rejeito e descartado sem qualquer aproveitamento. Porém, Vellinga \& Eisma (2005) destacam que em portos de países como Holanda e Estados Unidos, por exemplo, o sedimento oriundo da dragagem é visto como um recurso, pois além de todas as vantagens de se reaproveitar esse material em terra (construção de aterros, fabricação de tijolos, adubo, etc.), existe uma preocupação quanto ao descarte em mar aberto (Manap \& Voulvoulis, 2015).

Uma parte substancial do material dragado é composta de sedimentos limpos, sem contaminação, podendo ser utilizada sem necessidade de tratamento (Hinchee, 2002). Por outro lado, a contaminação de parte dos sedimentos encontrados nos fundos aquáticos, tanto de água salgada, quanto de água doce, torna cada vez mais problemática a sua disposição em qualquer sítio. Estima-se que cerca de 10\% de todo o material dragado nos portos mundiais seja contaminado (Hinchee, 2002; Castiglia, 2008; Monteiro, 2008; Castro \& Almeida, 2012). A preocupação ambiental vem impondo medidas restritivas ao uso desses sedimentos, especialmente no caso de conterem pesticidas, bifenilas policloradas (BPCs), hidrocarbonetos policíclicos aromáticos (HPAs) e metais pesados, como cádmio $(\mathrm{Cd})$, mercúrio $(\mathrm{Hg})$ ou chumbo (Pb) (Castiglia, 2006). Assim, a manutenção das profundidades dos canais de navegação em portos apresentam dificuldades crescentes em sua execução. Como a remoção de material do fundo é essencial para a realização de um grande número de obras situadas em meios aquáticos, o problema se mostra cada vez mais crítico, sendo necessário equacioná-lo por meio de processos voltados a cada caso.

Os custos de confinamento do material dragado contaminado são substancialmente mais elevados do que o simples despejo em mar aberto, prática usual até algum tempo atrás. Estima-se que o custo da disposição dos sedimentos em áreas confinadas especiais, ou 
do confinamento in situ do material dragado utilizado para isolar os sedimentos, pode ser de 3 a 6 vezes superior à simples descarga no mar (Hinchee, 2002). Entretanto, a forma mais eficaz de redução dos custos dos projetos de dragagem é, evidentemente, a utilização do material removido em usos benéficos como, por exemplo, no caso dos aterros controlados, onde se podem buscar condições de deposição não nocivas à natureza.

No caso do porto de Rio Grande, RS (extremo sul do Brasil), o uso benéfico e disposição de material dragado em terra já fez parte da antiga rotina de dragagem de seu canal de acesso, porém, desde os anos 2000 todos os descartes foram realizados em sítios de despejo localizados no oceano, à aproximadamente 25 km da costa da praia do Cassino (MRS, 2007).

Concomitante a este tipo de deposição, nos últimos 30 anos, pelo menos 25 deposições de lama fluída ocorreram ao longo da praia do Cassino, balneário contíguo aos molhes de fixação da barra da Lagoa dos Patos, onde está localizado o Porto de Rio Grande (Calliari, et al. 2020). Este tipo de depósito foi primeiramente registrado por Delaney (1965), o qual atribuiu como fonte original dos sedimentos a carga em suspensão da Lagoa dos Patos. A primeira menção à origem da lama sempre atribuiu uma fonte exclusivamente natural para os depósitos. No entanto, novas interpretações e dados recentes indicam que o aumento de volumes dragados ao longo dos anos refletiu na acentuação da frequência de deposições de lama na praia do Cassino (Calliari, et al. 2020).

As correntes geradas por ventos e tempestades nos quadrantes Norte e, principalmente, Sul fornecem condições de instabilidade de sedimentos finos nos locais de disposição com componentes de fluxo paralelos e diretos para a costa, independentemente da ação das ondas (Calliari et al., 2020). A modelagem hidrodinâmica indica que os sedimentos dispostos no estuário e na superfície da costa durante os ventos nordeste e sul têm o potencial de serem direcionados para a praia (Vieira, 2014). Calliari et al. (2020) identificaram, ainda, a deposição maciça de milhões de organismos após eventos de dragagem, o que não se configura como um processo natural, mas sim como uma indicação das atividades de dragagem.

A dragagem pode ser uma parte importante do impacto ambiental na praia do Cassino, porque o processo de acumulação natural é amplificado por pulsos intensos de sedimentos finos em pouco tempo, favorecendo deposições mais frequentes, uma vez que os locais históricos e atuais de descarte não são adequados e os procedimentos atuais de overflow e overboard injetam lama fluída diretamente no ambiente (Calliari et al., 2020). Decorrente disto citam-se alguns impactos negativos como redução do fluxo de turistas, alterações morfodinâmicas e mortalidade maciça da fauna bentônica (Calliari et al, op. cit).

Neste contexto, o presente trabalho visa identificar uma alternativa de disposição em terra dos sedimentos oriundos das obras de dragagem do Porto de Rio Grande, localizado no extremo sul do Brasil, o qual venha a se contrapor ao atual método de descarte em mar aberto.

\section{2 Área de estudo}

O porto de Rio Grande e a Ilha do Terrapleno de Leste estão inseridos no município de Rio Grande, situado às margens da Lagoa dos Patos, mais especificamente em sua porção estuarina. Essa região localiza-se na planície costeira do Rio Grande do Sul, a qual se constitui de uma costa arenosa, retilínea, baixa, sendo uma das mais amplas planícies costeiras do Brasil (Tomazelli \& Villwock, 1996). Situada entre as coordenadas $30^{\circ}$ e $32^{\circ} \mathrm{S}$ e orientada no sentido NE - SO, a Lagoa dos Patos tem cerca de $250 \mathrm{~km}$ de extensão e uma largura média de $40 \mathrm{~km}$. Por ter uma profundidade média de $5 \mathrm{~m}$ é classificada como um corpo d'água raso. Com uma área 10.360 km², constitui-se na maior área lagunar da América Latina e está entre as maiores lagoas do mundo (Herz, 1977; Castelão \& Moller, 2003).

A bacia Atlântica, onde está inserida a Lagoa dos Patos, drena uma área aproximada de $200.000 \mathrm{~km}^{2}$. Com isto, mais de um milhão de $\mathrm{m}^{3}$ /ano de sedimentos são carregados e desembocam na região estuarina (Villowck \& Tomazelli, 1995; Santos et al., 2004). Os picos 
de descargas de água doce estão associados às estações de inverno ou primavera, sendo que a dinâmica da laguna os Patos é claramente dominada pelo regime de ventos atuantes e pela passagem de frentes. Os ventos dominantes na região são provenientes do quadrante norte $\mathrm{e}$ nordeste ocorrendo duranteo ano todo, com maior intensidade nos meses de primavera e verão. Nos meses de outono e inverno a ocorrência de ventos do quadrante sul e sudoeste aumenta em função da passagem de frentes frias. Associados ao regime pluviométrico e de marés, estes ventos condicionam a variação dos níveis da laguna e o padrão de circulação na região do estuário (Castelão \& Moller, 2003).

Ao sul, a Lagoa dos Patos comunica-se com o mar entre os municípios de Rio Grande e São José do Norte, através do Canal do Norte na Barra do Rio Grande, onde foram construídos no início do século $X X$, dois molhes convergentes com blocos rochosos destinados à melhoria das condições de transposição da barra e que são denominados "molhes da barra" (Calliari et al. 2010). O porto de Rio Grande está localizado na margem oeste do Canal do Norte, que liga a Lagoa dos Patos ao oceano Atlântico (Fig. 1).

A zona portuária de Rio Grande é dividida entre o Porto Velho, Porto Novo e Superporto (Fig. 1). O Porto Velho, com $640 \mathrm{~m}$ de cais e profundidade aproximada de 2 a $5 \mathrm{~m}$, possui múltiplas destinações como terminal pesqueiro, de passageiros, área de turismo, lazer e militar (Capitania dos Portos e Distrito Naval). Já o Porto Novo é uma bacia de evolução onde os navios têm espaço para manobras constituído de dois canais de ligação, um com o Porto Velho e outro com o Canal do Norte (a grande via de navegação). Este porto apresenta $1952 \mathrm{~m}$ de cais e profundidade aproximada de 8 a $10 \mathrm{~m}$, contendo os terminais para carga geral, granéis sólidos e líquidos, containers e fertilizantes. Em 2004 foi inaugurada uma reforma de aproximadamente $300 \mathrm{~m}$ de cais novo, o qual permite operações de roll/on-roll/off.

A Ilha do Terrapleno de Leste é uma área situada em frente ao Porto Novo de Rio Grande (Fig. 2), ocupada há décadas pela Marinha do Brasil, com as instalações do $5^{\circ}$ Esquadrão de Helicópteros, a Estação de Rádio da Marinha do
Brasil e o Serviço de Sinalização Náutica do Sul.

Devido às suas características fisiográficas, sua localização estratégica e, principalmente, por ser uma ilha artificial formada pelo lançamento de sedimento dragado no passado, esta ilha constitui-se como a principal área de interesse do presente estudo.

\section{Materiais e métodos}

Os métodos aplicados nesta pesquisa foram estabelecidos a partir de um encadeamento lógico que tem como ponto de partida a análise bibliográfica do histórico de dragagens do Porto de Rio Grande. Foram analisadas áreas com potencial para disposição do material dragado em terra, na área imediata ao complexo portuário e nas suas proximidades, como por exemplo: Itha do Terrapleno de Leste; Ilha dos Marinheiros; Ilha da Torotama; Coroa-do-Boi e nas adjacências do Canal do Norte (Fig. 1). Para tanto, foram resgatados os históricos das dragagens, dos locais de disposição e dos aterros planejados no município de Rio Grande, os quais foram fundados com utilização de sedimento da dragagem. Esta análise prévia permitiu a elaboração de um panorama geral que acabou por direcionar as ações para a Ilha do Terrapleno, a qual foi selecionada para análise da potencialidade de sua utilização como local de deposição em terra de sedimentos dragados do porto de Rio Grande. A partir dessa definição, foram realizadas análises sedimentológicas em pontos específicos da Ilha, bem como uma análise da variação de sua linha de costa e, por fim, cálculos para definição de área e volume de sedimentos a serem depositados. Tal encadeamento metodológico é detalhado a seguir.

\subsection{Histórico da dragagem no Porto de Rio Grande}

Para resgatar o histórico das dragagens do porto de Rio Grande foi realizada uma revisão bibliográfica referente aos dados históricos da atividade, os quais foram obtidos em diferentes fontes de informações, como publicações científicas, registros da Superintendência do Porto de Rio Grande (SUPRG), Estudos e 


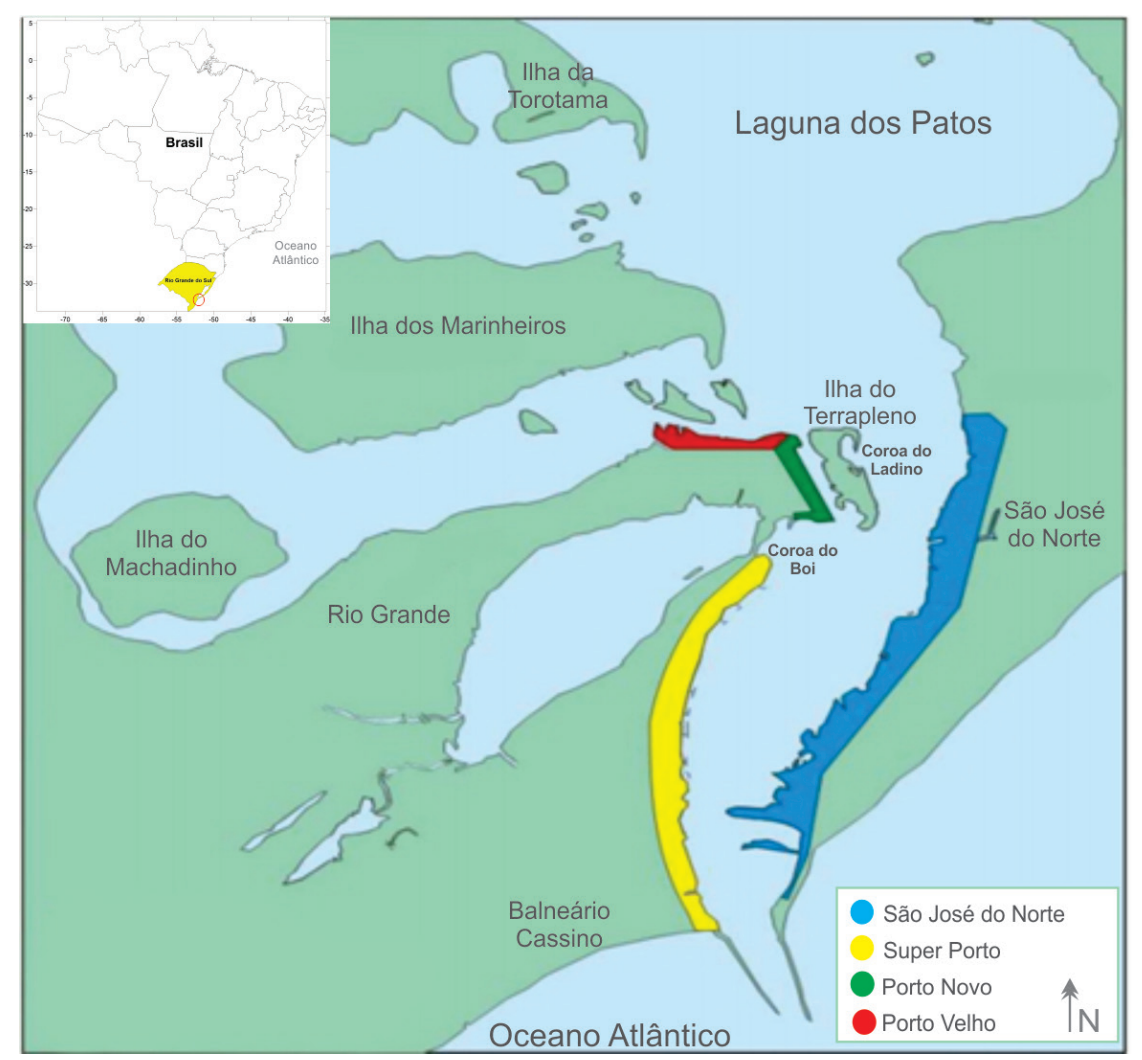

Figura 1. Localização da área de estudo, com destaque para as áreas do porto organizado de Rio Grande (adaptado de SUPRG, 2019).

Figure 1. Location map of the study area, with emphasis on the areas of the organized port of Rio Grande (adapted from SUPRG, 2019).

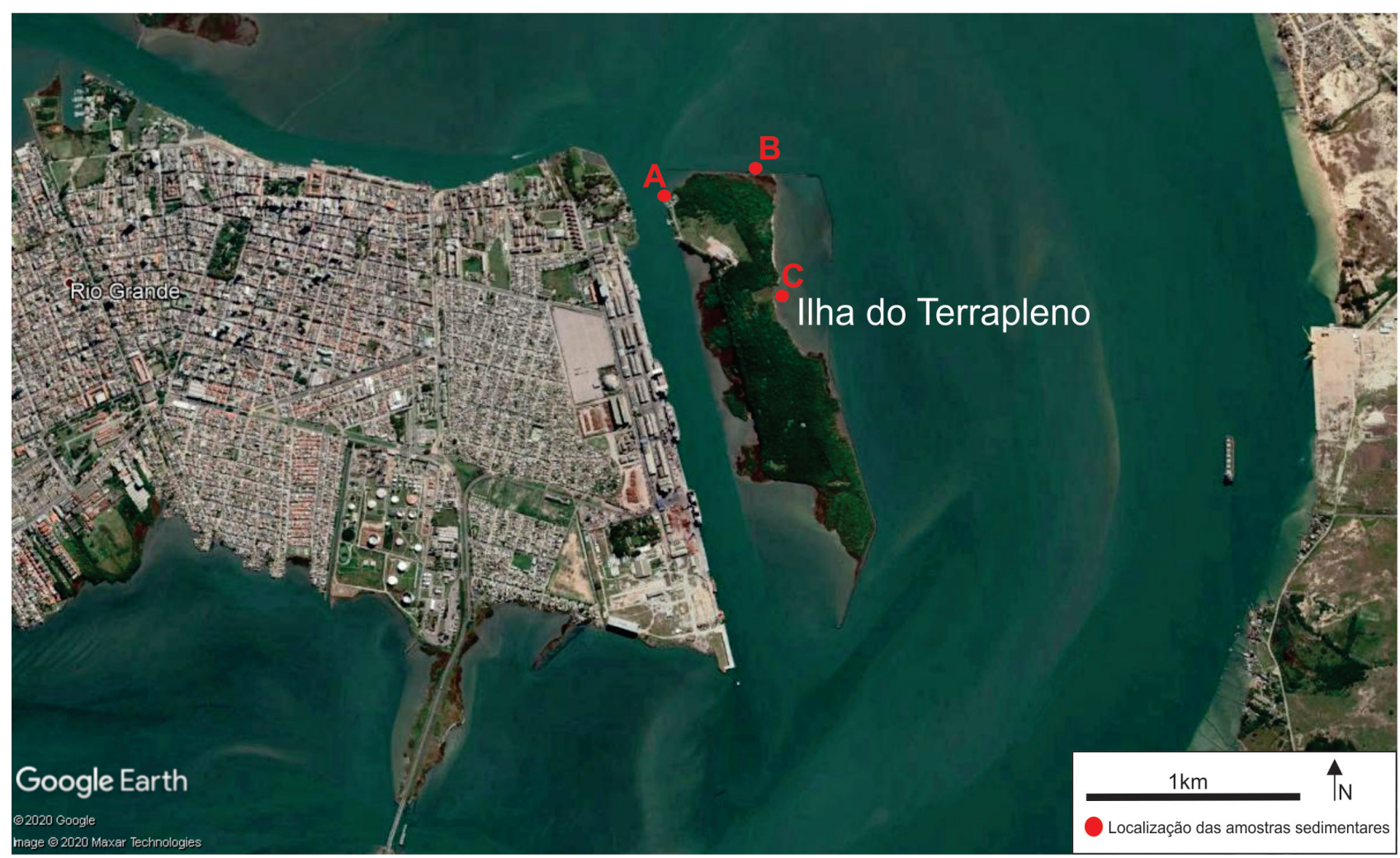

Figura 2. Localização da Ilha do Terrapleno de Leste, Rio Grande. Os pontos em vermelho representam os locais de amostragem para análise sedimentológica (fonte: Google Earth).

Figure 2. Location of Terrapleno de Leste Island, Rio Grande. The red dots represent the sampling sites for sedimentological analysis (source: Google Earth). 
Relatórios de Impactos Ambientais (EIA-RIMA's) de dragagens anteriores, além de outras fontes secundárias. Os resultados ilustram informações referentes aos últimos 60 anos da atividade sobre os volumes dragados, bem como sobre os locais onde o material foi retirado e posteriormente depositado.

\subsection{Análise granulométrica}

Em visita técnica realizada em Julho de 2018, foram selecionados três locais para amostragem de sedimentos (pontos A, B e C da Fig. 2) em diferentes setores das margens da Ilha do Terrapleno. A escolha dos pontos de coleta se deu em função da representatividade dos ambientes sedimentares existentes na região, contribuindo para uma melhor caracterização sedimentológica da área. A tabela 1 apresenta as coordenadas geográficas destas essas amostras.

Após coletadas e identificadas, as amostras foram encaminhadas para análise. Foram adotados os procedimentos de análise descritos por (Suguio, 1973; Garcia et al., 2008), sendo que o fluxograma da figura 3 sintetiza os procedimentos utilizados.

Os parâmetros estatísticos utilizados nestas classificações baseiam-se nametodologia de Folk \& Ward (1957) e foram aplicados via software Sysgran ${ }^{\circledR}$, o qual é específico para análises sedimentológicas. A classificação do sedimento do ponto de vista de tamanho do grão e composição foi obtida por meio do diagrama de Shepard.

\subsection{Variação da linha de costa}

Para determinação da variação da linha de costa na margem leste da Ilha do Terrapleno foram utilizadas imagens de satélite disponibilizadas no software Google Earth Pro, com uma resolução espacial de aproximadamente $1 \mathrm{~m}$ (obtidas com a maior resolução disponível - 4800 × 2255 pixels), viabilizando a vetorização da linha de costa da Ilha, entre os anos de 2004 e 2020. Crowell et al. (1999) e Leatherman et al. (2000) destacam que, em fotografias aéreas e imagens de satélites, um dos critérios para delimitação da linha de costa é a linha de preamar, sendo que a mesma pode ser definida como o limite entre a areia seca e a areia molhada (Toldo \& Almeida, 2003). As linhas de costa destas imagens foram vetorizadas e comparadas conforme a metodologia descrita em Thieler et al. (2009), determinando assim a taxa de erosão e a variação da linha de costa no local para estes 16 anos.

Essa área foi pré-definida para estudo devido às características fisiográficas do local, as quais, a princípio, indicam a viabilidade da deposição do material dragado, como por exemplo: maior taxa de erosão na margem leste da ilha devido sua exposição direta a dinâmica da Lagoa dos Patos. Tais características sugerem a necessidade da execução de obras de engenharia para recuperação da linha de costa, como por exemplo, o reforço do enrocamento pré-existente ao redor da área.

\subsection{Dados batimétricos e cálculo de volume}

Para calcular o volume de material dragado a ser disposto em área pré-defınida na Ilha do Terrapleno, foram utilizados dados de batimetria e medição da área. Essa mensuração da área foi realizada com a utilização do software Google Earth Pro, através de rotinas específicas no próprio programa. Já os dados batimétricos utilizados foram fornecidos por Antiqueira (2018).

Em um primeiro momento os arquivos de ponto (batimetria) foram convertidos em formato shape file, os quais foram interpolados a partir do método TIN (triangulate irregular network), gerando um arquivo de curvas de nível e, posteriormente, um modelo de elevação do terreno. O TIN é uma rede triangular que consiste em um modelo digital criado a partir de curvas de nível ou pontos cotados, onde ocorre a interpolação dos valores de altitude e profundidade por meio da criação de triângulos entre uma linha e outra, resultando em um modelo matemático com valores de altitude ou profundidade (Felgueiras et al., 2002). A partir destes dados de área e batimetria foi calculado o volume de sedimentos potencialmente passível de ser depositado nesta área com a utilização do software Arc.Gis ${ }^{\circledR}$. 
Tabela 1. Coordenadas geográficas (Lat-Long, datum SIRGAS 2000) dos pontos de coleta de sedimento na Ilha do Terrapleno Leste.

Table 1. Geographic coordinates (Lat-Long, datum SIRGAS 2000) of sediment collection points on the Terrapleno Leste Island.

\begin{tabular}{ccc}
\hline AMOSTRA & LATITUDE & LONGITUDE \\
\hline $\mathrm{A}$ & $32^{\circ} 01^{\prime} 54,5^{\prime \prime} \mathrm{S}$ & $52^{\circ} 04^{\prime} 30,4^{\prime \prime} \mathrm{O}$ \\
$\mathrm{B}$ & $32^{\circ} 01^{\prime} 48,6^{\prime \prime} \mathrm{S}$ & $52^{\circ} 04^{\prime} 28,0^{\prime \prime} \mathrm{O}$ \\
$\mathrm{C}$ & $32^{\circ} 02^{\prime} 08,8^{\prime \prime} \mathrm{S}$ & $52^{\circ} 04^{\prime} 10,1^{\prime \prime} \mathrm{O}$ \\
\hline
\end{tabular}

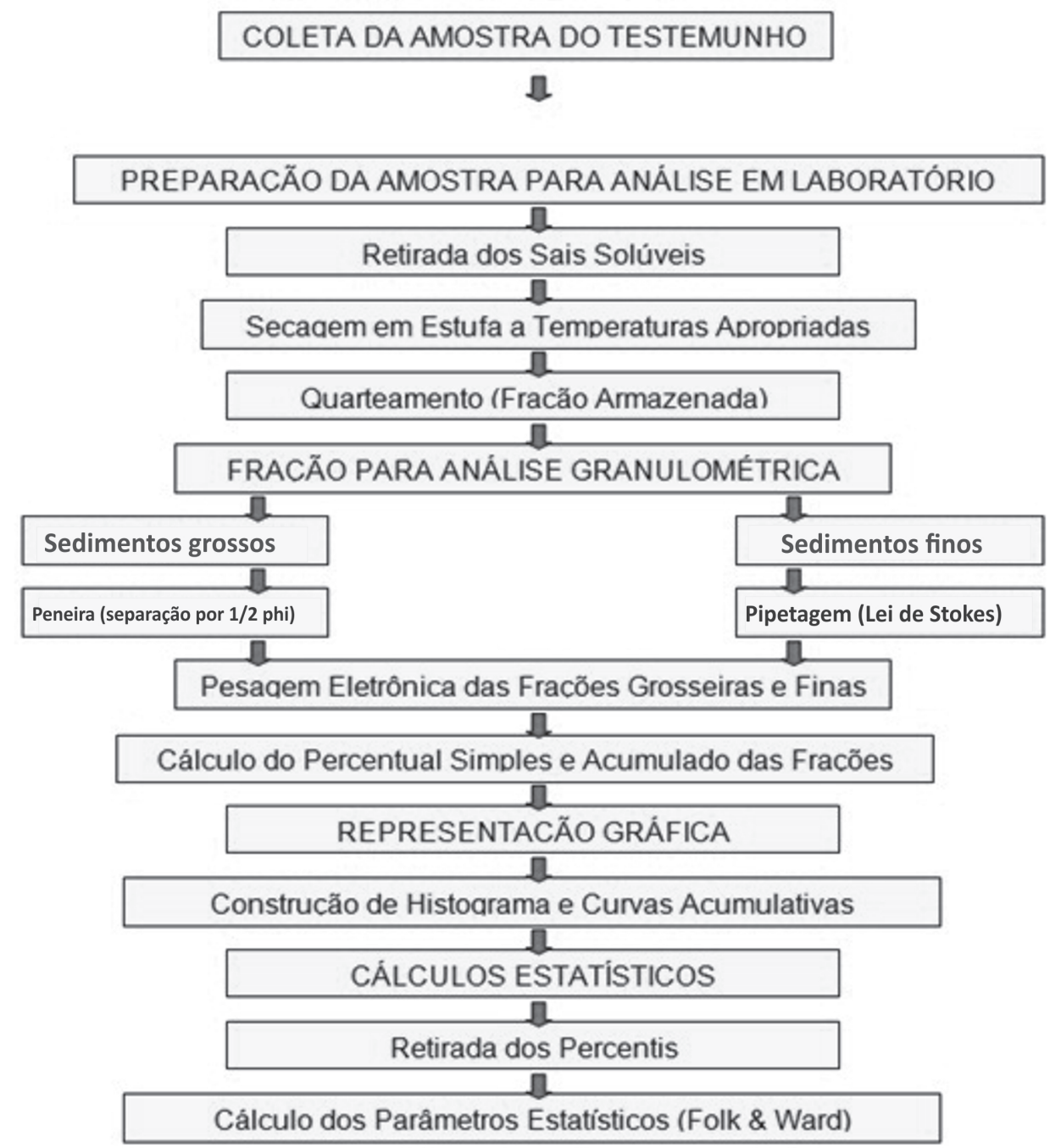

Figura 3. Fluxograma para análise granulométrica (adaptado de Garcia et al., 2008).

Figure 3. Flowchart for granulometric analysis (adapted from Garcia et al., 2008).

\section{Resultados e discussão}

4.1 Histórico da dragagem no Porto de Rio Grande: volumes e locais

A expansão do Porto de Rio Grande entre 1909 e 1914 gerou 8.776.000 $\mathrm{m}^{3}$ de material dragado, o qual foi utilizado para a construção de ilhas e, também, depositado ao longo das margens do estuário inferior da Lagoa dos Patos (Seeliger \& Costa, 1998). Após a finalização das obras de construção dos molhes da barra de Rio Grande em 1915, o momento de maior relevância ocorreu em 1961/62 quando o Departamento Nacional de Portos e Vias Navegáveis realizou a dragagem do canal entre o molhe e a barra, aumentando a sua profundidade para $12 \mathrm{~m}$. A partir deste período, dragagens contínuas passaram a ser necessárias. Na década de 1970, 
o canal foi dragado para profundidades da ordem de $14 \mathrm{~m}$, dando origem ao canal de acesso, sendo removidos $703.032 \mathrm{~m}^{3}$ de sedimentos (MRS, 2007). Entre 1980 e 1996, cerca de 24,5 milhões de $\mathrm{m}^{3}$ de sedimentos foram dragados do fundo do estuário para a manutenção da navegação, com uma média anual de 1.6 milhões $\mathrm{m}^{3}$. Deste total, cerca de $80 \%$ são provenientes do canal de acesso (Granato, 2005). Torres (2000) relata que a avaliação inicialmente prevista para uma dragagem realizada entre março e agosto de $1998\left(1.700 .000 \mathrm{~m}^{3}\right)$ foi aumentada em cerca de $40 \%$, com um volume total dragado de aproximadamente $2.940 .000 \mathrm{~m}^{3}$ (deste volume, $79,3 \%$ foi dragado no canal de acesso ao porto).

No período 1940-2000 foram removidos mais de 16 milhões de $\mathrm{m}^{3}$ de sedimentos, com destaque para as áreas do Porto Novo e Canal de acesso (Calliari et al., 2016) (Fig. 4).

Segundo Silva (2019), a variação do volume dragado anualmente entre 1998 e 2017 segue um padrão relativamente homogêneo, com valores que se aproximam de 4.000.000 de $\mathrm{m}^{3}$ alternando-se com anos onde não houve atividade de dragagem. Destaque é dado para o biênio 2009/2010 quando uma grande operação de dragagem retirou aproximadamente
20.000.000 $\mathrm{m}^{3}$ de sedimento dos canais de navegação do Porto de Rio Grande- RS (Fig. 5).

Em relação aos locais de descarte do material dragado nos canais do Porto de Rio Grande entre 1940 e 2000, destacam-se os volumes expressivos depositados em terra, principalmente nas ilhas Terrapleno de Leste e Oeste, mas também em outras localidades como a Coroa da Mariana, onde o material era lançado na parte subaquosa em profundidades de $8 \mathrm{~m}$ (Fig. 6).

Esses resultados corroboraram com a pré-seleção da Ilha do Terrapleno como área prioritária para despejo de material dragado, pois comprovam que historicamente já houve descartes em terra com o consequente uso benéfico de sedimento retirado dos canais de navegação do Porto de Rio Grande.

\subsection{Histórico de formação da Ilha do Terrapleno de Leste}

A Ilha do Terrapleno de Leste é uma ilha artificial formada através da deposição do sedimento dragado no canal do Porto Novo de Rio Grande. Existia a necessidade de se reduzir o tempo de acesso ao canal do Norte (maior

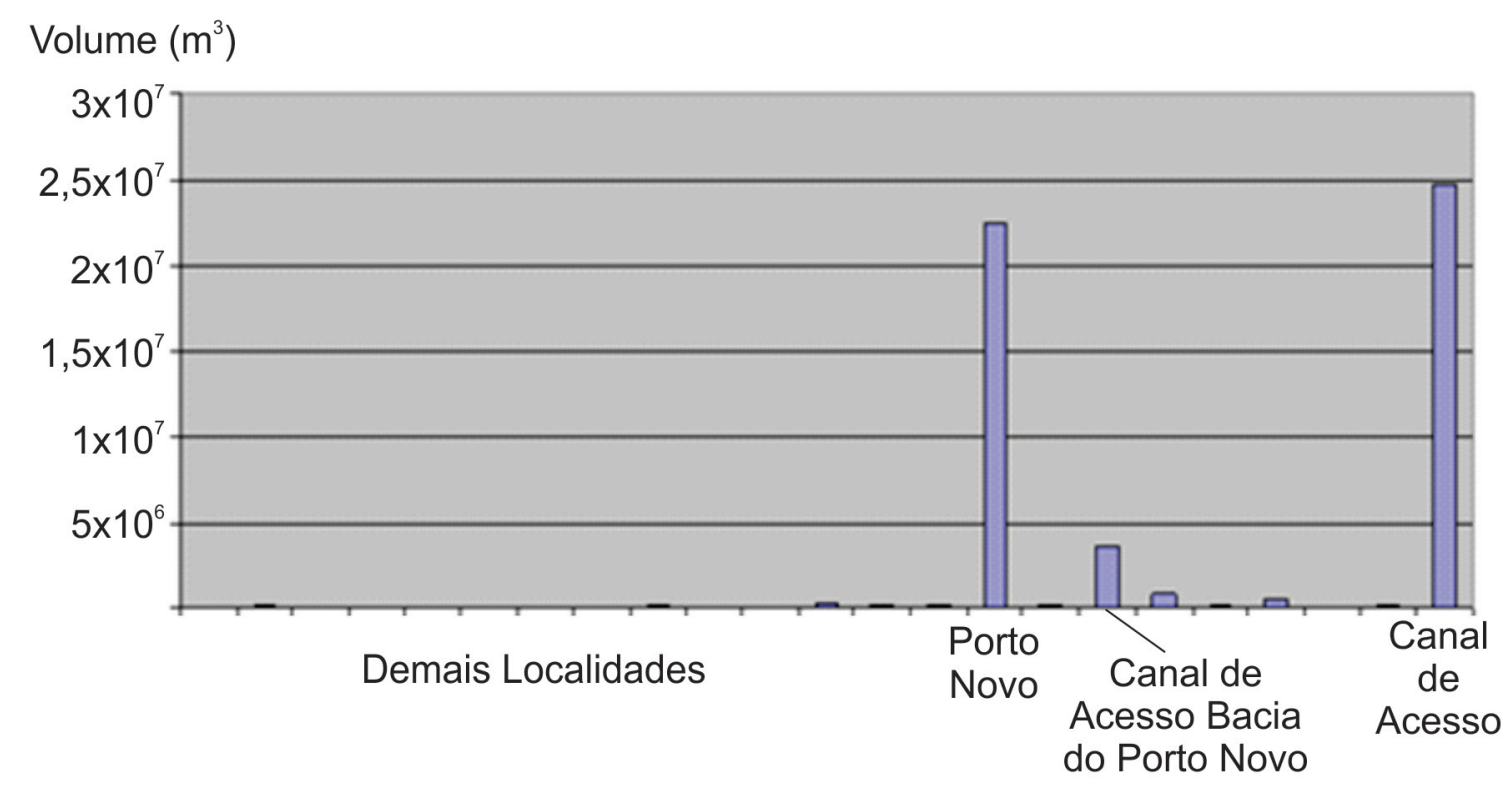

Figura 4. Volume dragado entre 1940 e 2000 nos canais do Porto de Rio Grande (adaptado de Calliari et al., 2016). Figure 4. Volume dredged between 1940 and 2000 in the channels of the Port of Rio Grande (adapted from Calliari et al., 2016). 


\section{Volume dragado anualmente $\left(\mathrm{m}^{3}\right)$}

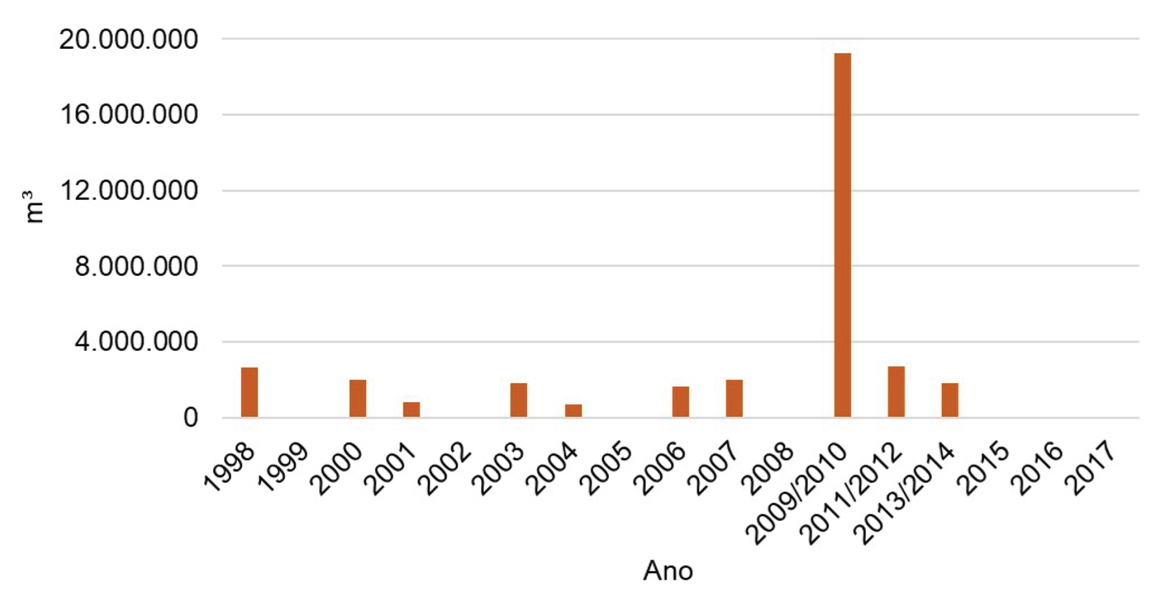

\begin{tabular}{|c|c|}
\hline Ano & Volume $\left(\mathbf{m}^{\mathbf{3}}\right)$ \\
\hline 1998 & $2.626 .413,10$ \\
\hline 1999 & 0,00 \\
\hline 2000 & $1.987 .158,34$ \\
\hline 2001 & $840.653,31$ \\
\hline 2002 & 0,00 \\
\hline 2003 & $1.846 .363,00$ \\
\hline 2004 & $686.506,30$ \\
\hline 2005 & 0,00 \\
\hline 2006 & $1.630 .592,00$ \\
\hline 2007 & $1.990 .831,00$ \\
\hline 2008 & 0,00 \\
\hline $2009 / 2010$ & $19.285 .192,57$ \\
\hline $2011 / 2012$ & $2.729 .875,00$ \\
\hline $2013 / 2014$ & $1.796 .189,90$ \\
\hline 2015 & 0,00 \\
\hline 2016 & 0,00 \\
\hline 2017 & 0,00 \\
\hline
\end{tabular}

Figura 5. Volume dragado entre 1998 e 2017 nos canais do Porto de Rio Grande (Silva, 2019).

Figure 5. Volume dredged between 1998 and 2017 in the channels of the Port of Rio Grande (Silva, 2019).

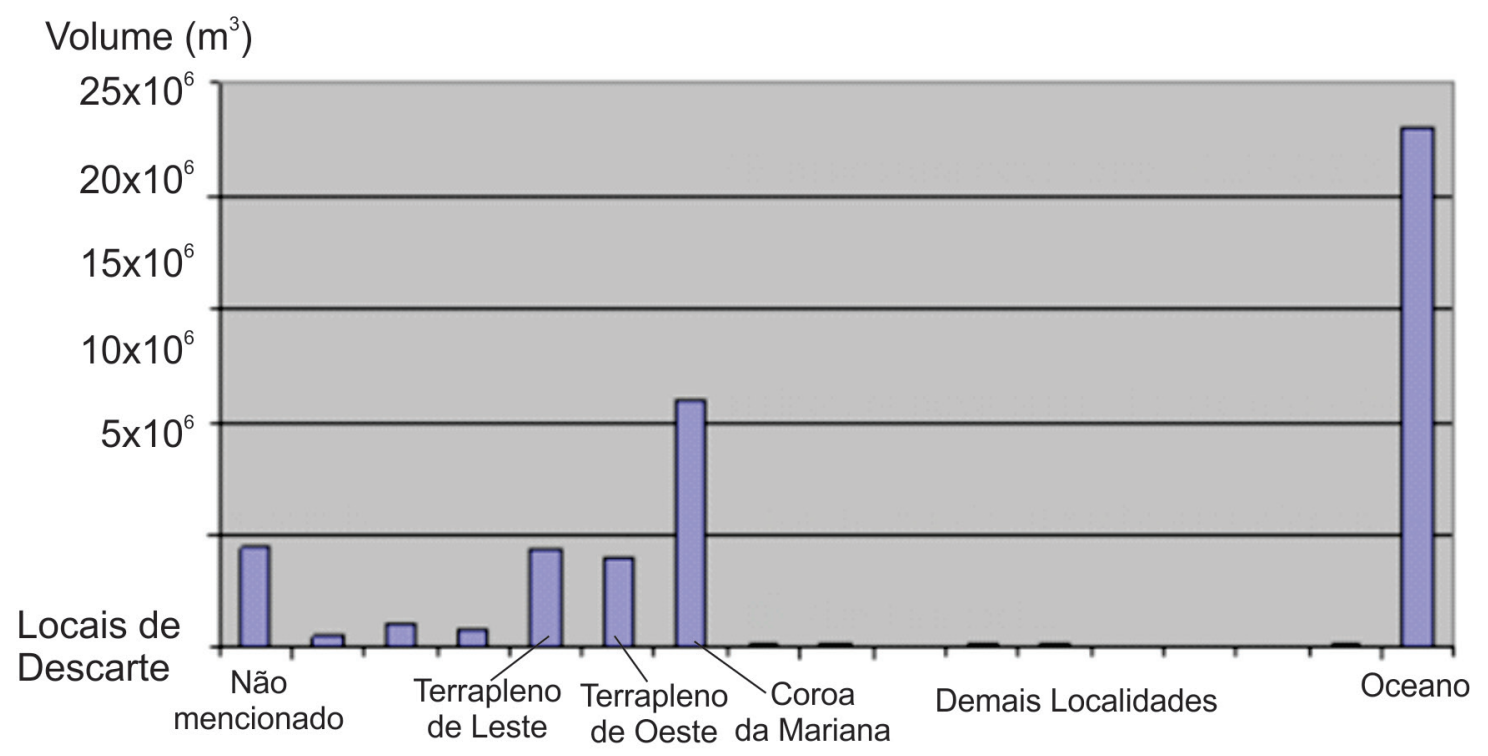

Figura 6. Locais de descarte do material dragado nos canais do Porto de Rio Grande (adaptado de Calliari et al., 2016). Figure 6. Places for disposal of dredged material in the channels of the Port of Rio Grande (adapted from Calliari et al., 2016).

via navegável) a partir do Porto Velho. Segundo Neu (2011), uma das soluções seria efetuar isso através da abertura de um uma bacia portuária com dois canais de ligação ao norte e ao sul desta (Porto Novo). As obras de construção do Porto Novo começaram pela dragagem da bacia de evolução e do seu canal de acesso, dandoIhes a profundidade de 10,4 m, e formando, com o produto da dragagem duas ilhas denominadas de Terraplenos Leste e Oeste, esta última com
200 ha de superfície (Fig. 7). Neste processo foram remobilizados cerca de $8.776 .000 \mathrm{~m}^{3}$ de sedimentos. Praticamente metade deste volume foi para o aterro da área que deu origem à estrutura portuária e a outra metade deu origem à Ilha do Terrapleno (DEPREC, 1939). Nesta dragagem, foram empregadas três dragas, sendo duas de sucção e uma de caçambas, além de um recalcador estacionário, uma frota de rebocadores e batelões lameiros. Nas obras, 
trabalhavam cerca de quatro mil operários de todas as categorias (IFPRC, 1926).

Embora à época os engenheiros tivessem manifestado a inconveniência da fixação do Porto Novo sobre a Coroa do Ladino, expondo que o local estaria sujeito a altas taxas de assoreamento devido às suas condições naturais - as quais provocariam movimento dos sedimentos por arrasto ou suspensão - o projeto foi aprovado e iniciado em setembro de 1908 (Calliari et al., 2010). Os rejeitos da dragagem foram empregados como aterro para a formação do Terrapleno de Leste e para a fixação da margem oeste, onde está situada a cidade de Rio Grande, o que provocou impactos expressivos nas características hidrodinâmicas e sedimentares naturais (Calliari et al., 2010).

A Figura 7 ilustra o processo histórico de construção da Ilha do Terrapleno a partir da deposição sedimentos dragados do canal de navegação do Porto de Rio Grande, com o detalhamento de três momentos específicos: 1891 (fıg. 7A), 1921 (fig. 7B) e 1944 (fig. 7C). Após sua construção, a Ilha do Terrapleno de Leste permaneceu sem qualquer tipo de uso por duas décadas. Em 1935, a ilha recebeu as primeiras instalações de uma estação de rádio para atender as necessidades do Ministério da Marinha, que planejava ampliar suas instalações na cidade. Em 1936 foi criada na ilha a Base de Aviação Naval do Rio Grande do Sul. Em 1937 é criado o Aeroclube da cidade do Rio Grande, cujas atividades de formação e treinamento de aviadores realizavam-se neste local, mais especificamente nas instalações da Base de Aviação Naval (Costa, 2002; Dumith et al., 2008; Telles, 2011).

O começo dos anos de 1980 significou um novo momento para a Ilha do Terrapleno de Leste, por conta da decisão do Ministério da Marinha de transferir para Rio Grande a sede do Comando do $5^{\circ}$ Distrito Naval, então baseado em Florianópolis - SC (Costa, 2002). Atualmente, na ilha estão situadas três organizações Militares: - $5^{\circ}$ Esquadrão de Helicópteros de Emprego Geral (HU-5) e Estação Radiogoniométrica da Marinha em Rio Grande (ERMRG) e o Serviço de Sinalização Náutica do Sul (SSN-5) (DOCM, 2014).

\subsection{Análise granulométrica do sedimento da Ilha do Terrapleno}

A tabela 2 e as figuras $8 \mathrm{~A}, 8 \mathrm{~B}$ e $8 \mathrm{C}$ apresentam os resultados das análises granulométricas para as amostras $A, B$ e $C$, em termos de percentuais de cascalho, areia, silte e argila, suas frequências acumuladas, bem como suas classificações no diagrama de Shepard (1954). A amostra A classifica-se como Areia Síltica; amostra B é Areia Síltico-Argilosa e a amostra C é Areia argilosa (Fig. 8b).

A definição das características da sedimentologia da Ilha do Terrapleno é crucial para que se possa compará-la ao material dragado nos canais de navegação do porto de Rio Grande e áreas adjacentes. Tal comparação pode determinar se os locais em terra próximos aos canais seriam apropriados para disposição de material dragado, uma vez que estes estarão sujeitos as mesmas condições hidrodinâmicas. O material analisado apresenta um pacote sedimentar com intercalações de material silticoargiloso compactado e arenoso de granulometria fina a muito fina. Tais características são compatíveis, do ponto de vista granulométrico com os sedimentos dragados nos canais de navegação (Poyry, 2008). O fato de se tratar de um ambiente abrigado (laguna) faz com que a velocidade orbital das ondas junto ao fundo sejam os maiores vetores de erosão e transporte deste tipo de ambiente (Nicolodi et al., 2010), tornando a compatibilização do sedimento a ser depositado com as características hidrodinâmicas locais um critério fundamental.

Soma-se a isto, o fato de existir na margem leste da ilha um enrocamento construído para quebra de energia de ondas, que hoje se encontra parcialmente submerso, podendo ser recuperado com obra de engenharia adequada.

\subsection{Análise da variação da linha de costa da Ilha do Terrapleno}

Os níveis de água mais altos dentro do estuário somado aos ventos do quadrante Nordeste fazem com que as ondas incidam na margem leste da Ilha do Terrapleno, gerando um maior transporte de sedimentos nesse lado da 


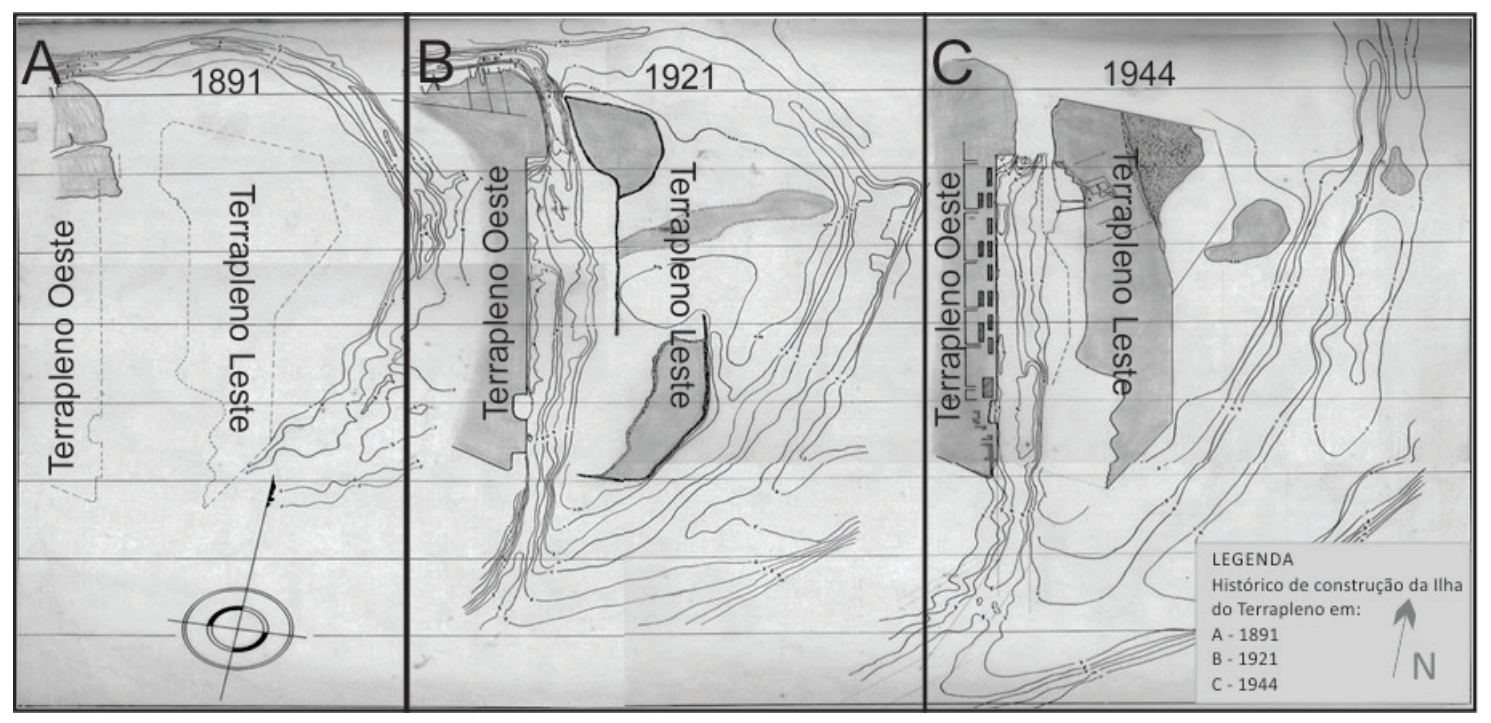

Figura 7. Evolução dos canais na Ilha do Terrapleno no período 1891-1944 (adaptado de Poyry, 2008). Figure 7. Evolution of channels on the Terrapleno Island (adapted from Poyry, 2008).

Tabela 2. Percentual de cascalho, areia, silte e argila do pacote sedimentar das amostras coletadas na Ilha do Terrapleno de Leste (amostras A, B e C).

Table 2. Percentage of gravel, sand, silt and clay from the sedimentary package of the samples collected on the Terrapleno Island in the East (samples $A, B$ and $C$ ).

\begin{tabular}{ccccc}
\hline Amostra & \% Cascalho & \% Areia & \% Silte & \% Argila \\
\hline A & 0,45 & 70,13 & 24,64 & 4,77 \\
B & 0,08 & 56,79 & 31,63 & 11,5 \\
\hline C & 0,02 & 53,94 & 30,49 & 15,54 \\
\hline
\end{tabular}

A

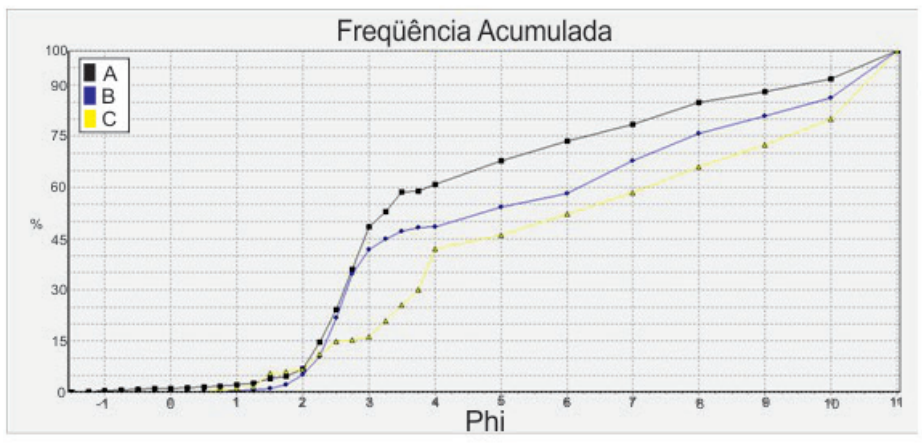

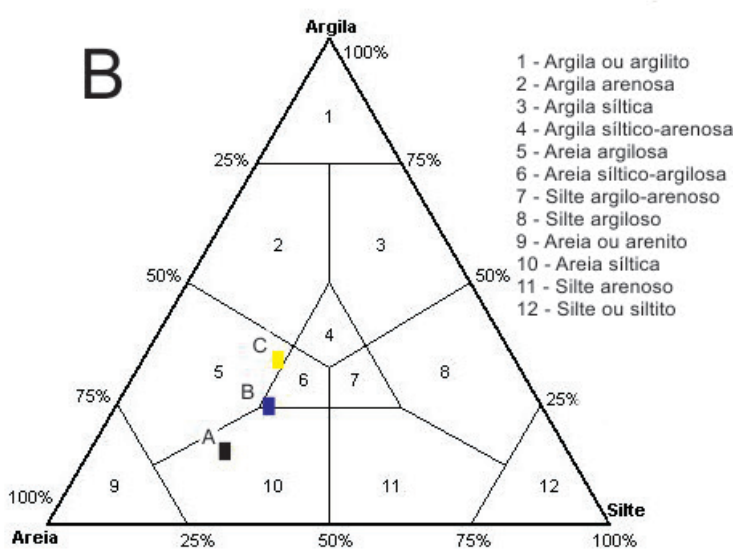

Figura 8. Resultados das análises sedimentológicas. A) Frequências acumuladas das 3 amostras, com base em phi; B) Classificação das amostras a partir do diagrama de Shepard (1954).

Figure 8. Results of sedimentological analyzes. A) Accumulated frequencies of the 3 samples, based on phi; B) Classification of samples based on the Shepard (1954) diagram. 
Ilha. No local, existe uma estrutura de proteção (enrocamento) projetada para fins de contenção da erosão, poréma mesma encontra-se submersa e, por consequência, não mais atenua a energia de ondas incidentes no local. Na margem oeste da Ilha onde se localiza grande parte da Bacia do Porto Novo, se nota a acresção da margem ao longo dos anos (Antiqueira, 2018) (Fig. 9). Tal fato pode ser explicado pelo baixo grau de exposição à dinâmica de vagas (sea) provindas de Nordeste e Leste, especialmente em condições de cheias como também pela fixação de sedimentos devida à vegetação de pântanos salgados (salt marshs). Assim, se efetivada uma solução de engenharia que aumentasse o enrocamento existente e a disposição do material dragado, os habitats (salt marshs) poderiam ser restaurados, o que auxiliaria no processo de estabilização da margem leste da Ilha do Terrapleno de Leste.

Com a aplicação do método de comparação de imagens de satélite oriundas do software Google Earth, verificou-se a erosão da Ilha do Terrapleno de Leste entre 2004 e 2020 especificamente na margem leste, onde se localiza a Estação Radiogoniométrica da Marinha em Rio Grande (ERMRG). A existência desta estrutura denota relevância em termos de uso deste espaço, uma vez que presta serviços importantes para a comunidade. Estimou-se que a taxa de remoção de sedimentos dessa porção da ilha seja de cerca de $1 \mathrm{~m} / \mathrm{ano}$ no período analisado (Fig. 10).

Este processo erosivo é também documentado por meio do "Relatório da erosão do Parque de Antenas", organizado pela Marinha do Brasil (2014) e que confirma, a partir de registros fotográficos, a retrogradação das margens e sua evolução ao longo dos anos, além do comprometimento de algumas edificações e construções existentes no local (Fig. 11).

Além da Ilha do Terrapleno, a erosão das margens também é observada com maior significância na Ilha da Torotama e Ilha dos Marinheiros (Fig. 1). A perda de sedimentos nessas áreas causa problemas relacionados à diminuição de habitats, destruição de edificações e trapiches de pesca, gerando prejuízos às comunidades das ilhas.

\subsection{Cálculo de volume de material na área definida}

Devido à proximidade do canal de navegação e existência de uma pré-estrutura de contenção (enrocamento submerso), definiu-se como local prioritário de descarte do material dragado uma área específica com um total de 263.146 $\mathrm{m}^{2}$ que contorna a margem leste da Ilha do Terrapleno e acompanha o enrocamento já existente no local.

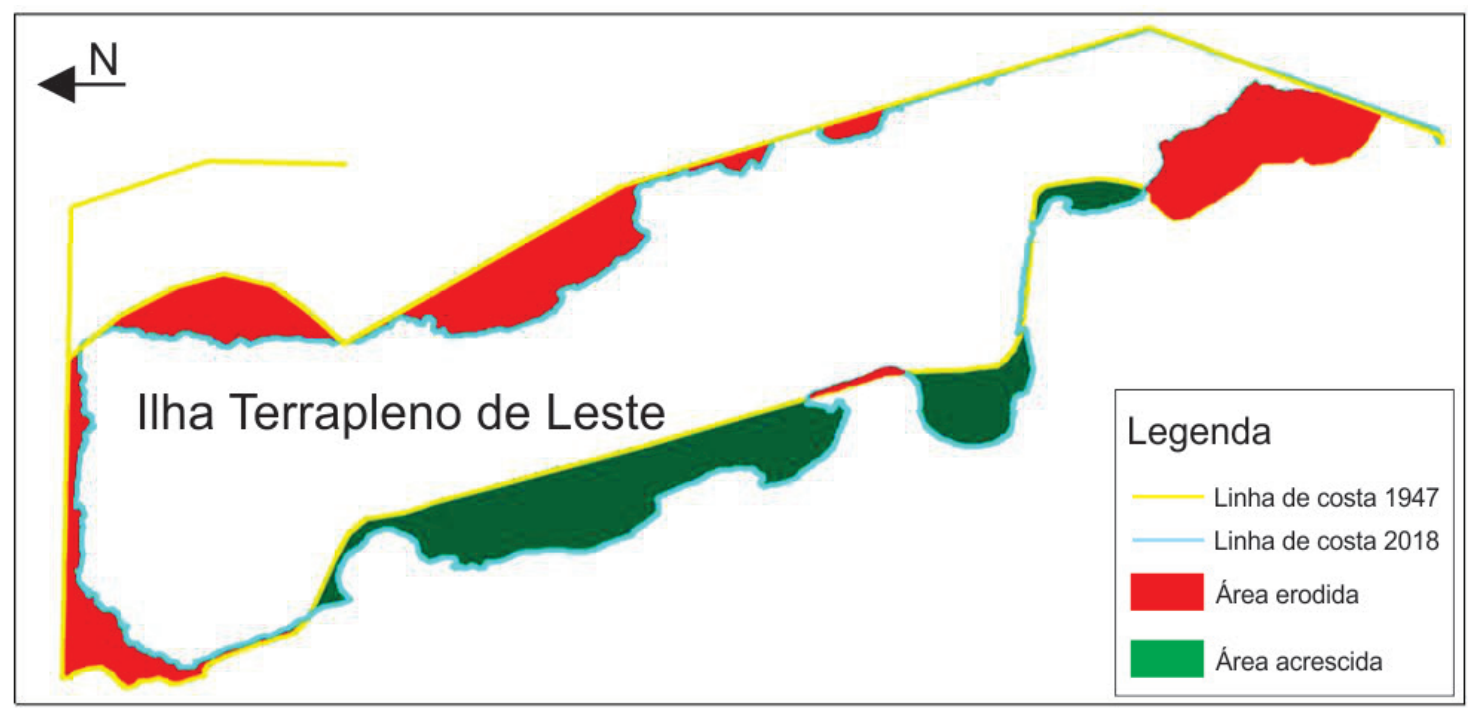

Figura 9. Erosão e acresção da Ilha do Terrapleno de Leste entre os anos de 1947 e 2018 (Antiqueira, 2018). Figure 9. Erosion and progradation of the Terrapleno de Leste Island between the years 1947 and 2018 (Antiqueira, 2018). 


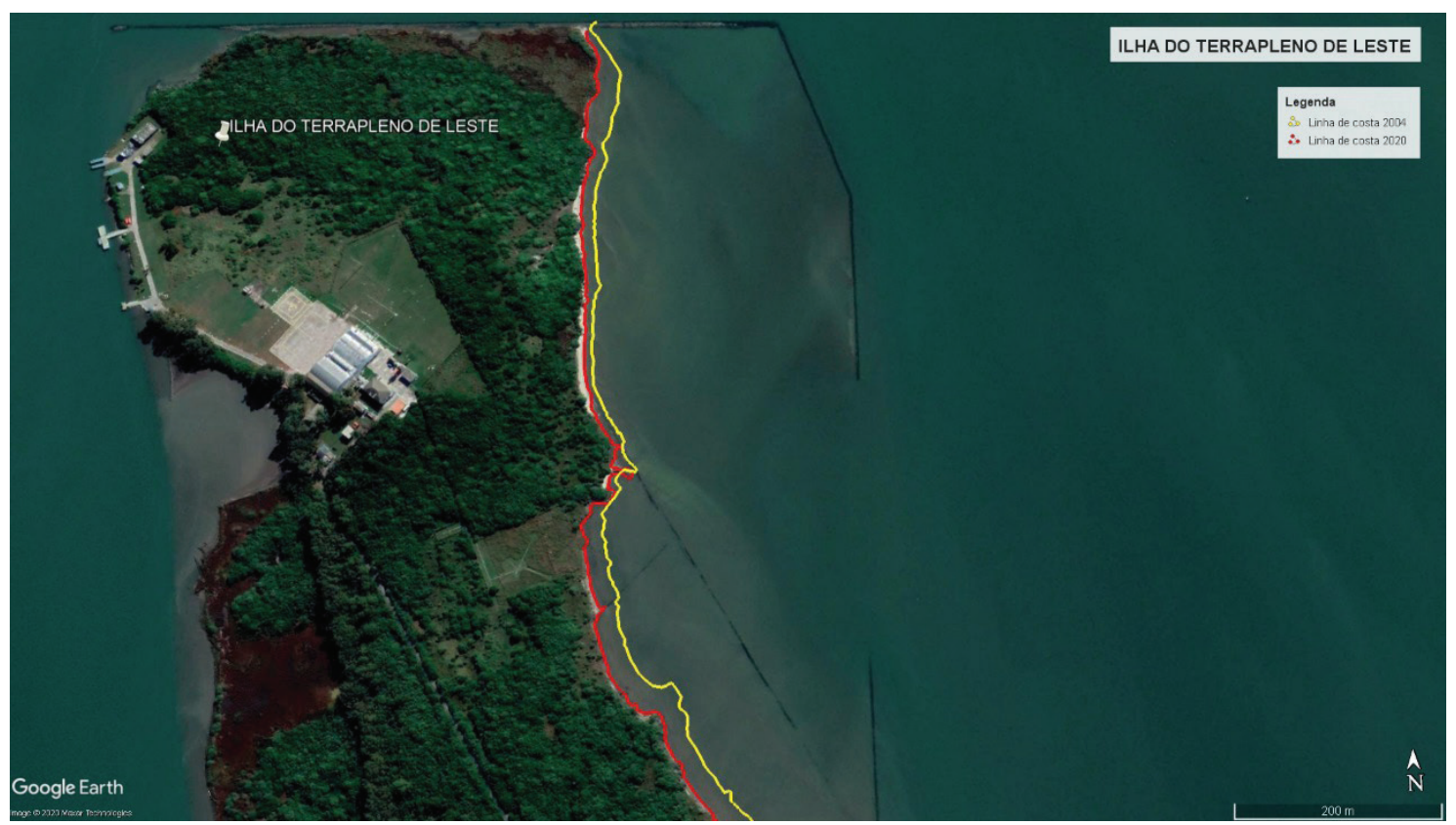

Figura 10. Variação da linha de costa na margem leste da Ilha do Terrapleno entre 2004 e 2020.

Figure 10. Variation of the east coastline of Terrapleno Island between 2004 and 2020.

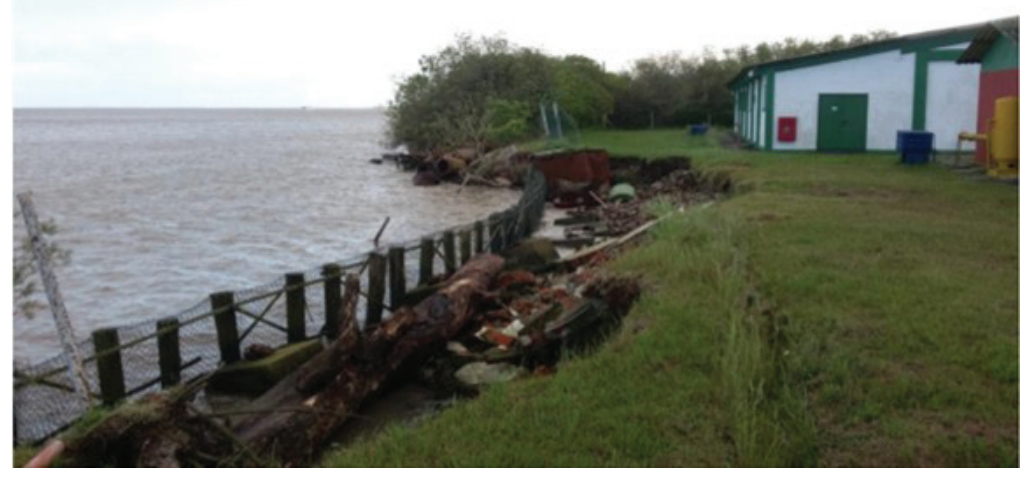

Figura 11. Erosão na margem da Ilha do Terrapleno de leste. Fonte: Villwock, (2019).

Figure 11. Erosion on the eastern coastline of the Terrapleno Island. Source: Villwock, (2019).

Com base nos dados batimétricos obtidos por Antiqueira (2018), foi definido o volume de material a ser depositado na área selecionada, dentro de um recorte específico na área de interesse para depósito do material dragado. A partir das informações de área e profundidade, foi efetuado o cálculo cujo resultado expressa o volume (em milhões de metros cúbicos) de sedimento que a área suportaria.

Este cálculo de volume mostra que o local pode acomodar a deposição de 3,972 milhões de $\mathrm{m}^{3}$ de sedimentos (Fig. 12). Este valor é expressivo quando comparado ao volume total dragado nos últimos anos no Porto de Rio Grande, que é de 18,736 milhões de $\mathrm{m}^{3}$, conforme o Programa Nacional de Dragagem (PND2). O volume potencial de deposição na área selecionada equivale a $21,19 \%$ do volume total dragado, considerando apenas esta única área potencial para descarte aqui identificada.

\subsection{Proposta de deposição do material dragado}

A atual proposta parte da premissa de que a dragagem de manutenção, ou seja, a remoção do material de assoreamento depositado no leito dos canais por meio de um processo natural, é necessária a fim de se manter as profundidades de projeto dos canais de navegação e portos (Almeida, 2004). 


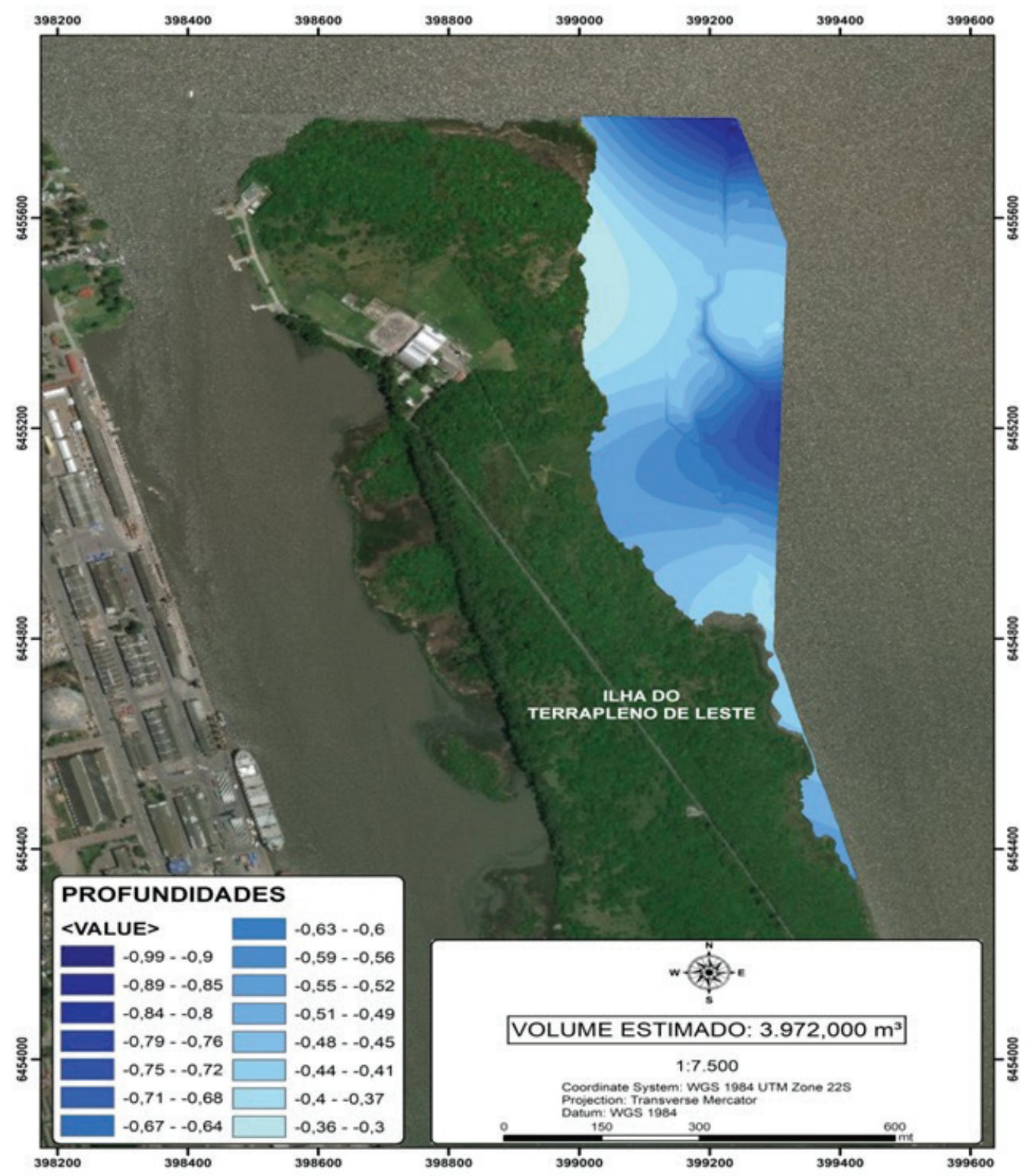

Figura 12. Cálculo do volume de material em relação à capacidade da área para despejo.

Figure 12. Calculation of the volume of material in relation to the area's capacity for disposal.

Cerca de $90 \%$ do material dragado no mundo situa-se abaixo dos níveis de contaminação normalmente considerados como inaceitáveis sendo, assim, passíveis de serem utilizados para usos benéficos (Goes Filho, 2004), ou seja, seguindo a legislação de cada país e avaliando os impactos ambientais da disposição do material dragado, podem-se buscar alternativas que aumentem seus usos benéficos e meios que reduzam os efeitos adversos da disposição desse material em mar aberto.

No Brasil, a resolução CONAMA 454/2012 estabelece as diretrizes gerais e os procedimentos referenciais para o gerenciamento do material a ser dragado em águas sob jurisdição nacional (CONAMA, 2012). A gama de aplicações para o material dragado é bastante variada, sendo limitada apenas pela engenhosidade e experiência dos projetos (USACE, 1987). Uma vez que o uso benéfico do material dragado depende, fundamentalmente, da sua composição e de sua distribuição granulométrica, a definição destes parâmetros permite traçar as faixas de uso para o material e, a partir da avaliação das condições operacionais utilizadas para sua remoção, de sua aceitabilidade ambiental e de seus custos, indicar um destino benéfico apropriado para cada tipo de material (Hermanns, 2017). 
Uma das maiores preocupações ao estabelecer a proposta de descarte de material dragado em terra, é a questão da possibilidade da presença de contaminantes no sedimento (Volpato et al., 2017), o que dificultaria sua deposição (Choueiri et al. 2009; Torres et al. 2009). No caso do Porto de Rio Grande, a existência de estudos dessa natureza permite inferir que o grau de contaminação dos sedimentos dragados é baixo (Teixeira \& Dias, 2012). Embora não existam trabalhos mais recentes, análises presentes no Relatório de Impacto Ambiental para atividade de dragagem do Porto de Rio Grande (Poyry, 2008) e no Programa de Monitoramento Ambiental Portuário (Kitzmann \& Asmus, 2006) não apontaram, à época, problemas de contaminação dos sedimentos dragados no Porto de Rio Grande, estando todos os resultados dentro dos padrões da Resolução CONAMA 344/2004 (Asmus, 2006).

Burgueño (2009) avaliou os níveis de contaminação dos sedimentos do canal de acesso ao Porto de Rio Grande - RS, com vistas a sua disposição em terra e concluiu que os teores encontrados, quando comparados aos limites estabelecidos na legislação pertinente, denotam que os sedimentos dragados nos canais do porto de Rio Grande poderiam ser dispostos em terra sem impactos significativos ao ambiente. Evidentemente tal afırmação não exclui todas as obrigações legais de obtenção de licenças para tal atividade.

Considerando a metodologia aplicada e seus resultados, a Ilha do Terrapleno de leste foi definida como área prioritária para deposição em terra do material dragado nos canais do Porto de Rio Grande, devido à: a) histórico de formação da Ilha do Terrapleno; b) compatibilidade granulométrica do pacote sedimentar da Ilha com o sedimento dragado; c) erosão da linha de costa; d) batimetria e área definida para deposição do material; e) proximidade da Ilha do Terrapleno aos canais de navegação (1,5km); f) existência de estrutura de rochas (enrocamento artificial) ao redor da área definida.

A figura 13 destaca a área proposta na margem leste da Ilha do Terrapleno que seria preenchida com sedimento oriundo da dragagem. Observa-se na imagem o enrocamento existente ao redor da área.

A presente proposta aponta uma alternativa de deposição do material dragado que difere do atual método de descarte em mar aberto, ao passo que, atribui um uso benéfico ao material dragado no Porto de Rio Grande, o qual atualmente é despejado como um resíduo. Esta alternativa faz com que o sedimento dragado possa ser utilizado como um recurso, beneficiando ambas as partes interessadas: a Marinha do Brasil, que necessita conter a erosão das margens da Ilha do Terrapleno e a Superintendência do porto de Rio Grande (SUPRG), que busca por alternativas e locais para descarte do sedimento dragado nos seus canais de acesso.

A alternativa aqui discutida tem potencial para reduzir possíveis danos ambientais causados pelo descarte em mar aberto, principalmente no que diz respeito à deposição de lama fluida na praia do Cassino (Calliari et al. 2000; Mirlean et al. 2020). Ainda que não existam estudos conclusivos a respeito da origem dessa lama que possam definir o grau de contribuição do escoamento natural da Lagoa dos Patos e do volume de resíduos descartados durante as obras de dragagem no porto de Rio Grande, a tomada de decisão neste contexto deve se pautar pelo Principio da Precaução. Tal princípio se reporta à função principal de evitar os riscos e a ocorrência de danos ambientais, buscando um ato antecipado à ocorrência do impacto (Lacey, 2006).

Com base nesse princípio sugere-se que, independente da fonte geradora do impacto, deve-se considerar a hipótese da cumulatividade entre as duas teorias para a origem da incidência de lama fluida na Praia do Cassino: escoamento natural da Lagoa dos Patos e dragagem da área portuária. Com isso, deve-se optar por métodos de descarte que diminuam o volume de material lançado no oceano, evitando possíveis impactos ambientais negativos como alterações morfodinâmicas e mortalidade maciça da fauna bentônica, bem como o impacto causado às atividades de turismo e lazer (Calliari et al, 2020).

Neste cenário, o presente trabalho define um uso benéfico a esse material, sugerindo sua deposição em área pré-definida na margem leste da Ilha do Terrapleno de Leste (Fig. 14), podendo 


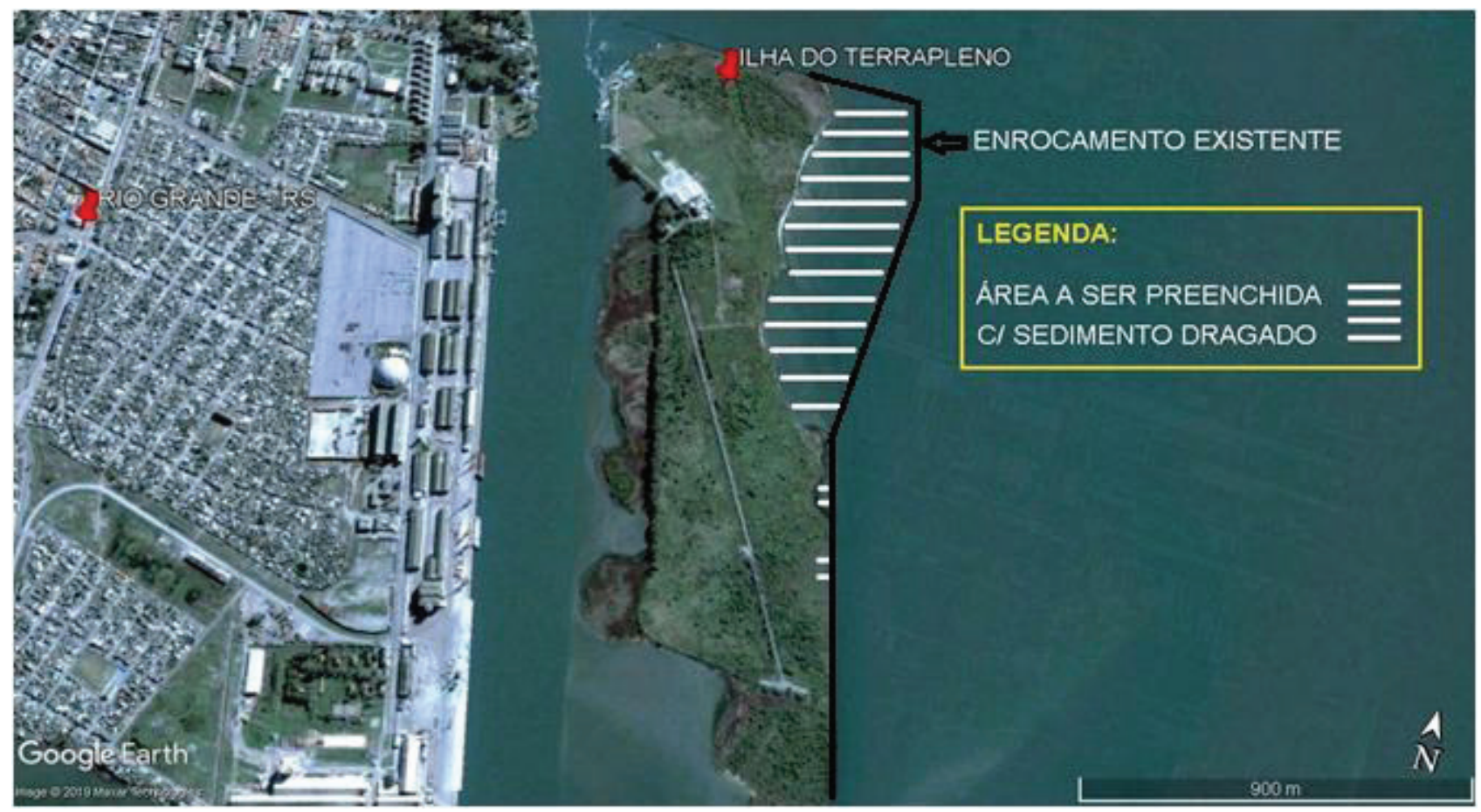

Figura 13. Área enrocada a ser preenchida com material dragado. Figure 13. Area to be filled with dredged material.

tal ação servir como projeto experimental e que, após sua execução, monitoramento e avaliação, poderia ser replicada em outras ilhas e localidades próximas aos canais de navegação dentro do estuário da Lagoa dos Patos.

Destaca-se ainda que os resultados obtidos podem auxiliar no processo de tomada de decisão sobre o descarte deste tipo de material, como recomenda o parecer técnico $n^{\circ}$ 50/2017 COMAR/CGMAC/DILIC, de 24/08/2017, onde o IBAMA sugere que "novas dragagens de manutenção não fossem autorizadas até que fosse apresentado estudo de alternativas locacionais para a disposição do sedimento".

\section{Conclusões}

Considerando o panorama atual de variação de linha de costa em todo o globo, o qual aponta para cenários erosivos em grande parte das zonas costeiras, estuários e sistemas lagunares, é inconcebível que alternativas de deposição em terra de sedimentos oriundos de dragagem não sejam apreciadas quando do planejamento da atividade.

Espera-se que os resultados aqui apresentados e discutidos sob a forma da proposta de área em terra para disposição dos sedimentos possam colaborar de duas formas: a primeira do ponto de vista conceitual, contribuindo ao fomento da discussão sobre o uso benéfico deste material em detrimento ao simples descarte em oceano aberto. Do ponto de vista da escala local, a expectativa é que esta análise seja considerada nos planos de dragagem do Porto de Rio Grande (RS), levando em consideração que já existem solicitações do órgão ambiental fiscalizador (IBAMA) à Superintendência do Porto de Rio Grande (SUPRG) de novos estudos e alternativas para dragagem no município.

A alternativa aqui apresentada de descarte do material dragado no Porto de Rio Grande na Ilha do Terrapleno visa aperfeiçoar o processo de gestão deste tipo de material, transformando-o de um potencial problema a ser mitigado (deposição na praia, por ex.) em uma solução para problemas específicos, como a erosão costeira em região estuarina. Iniciativas deste tipo, desde que bem planejadas e executadas, tendem a reduzir o esforço de gestão e aperfeiçoar a aplicação de recursos financeiros, bem como promover a consolidação de uma proposta para a disposição dos sedimentos das dragagens do porto de Rio Grande. 
Agradecimentos. Dedicamos este trabalho a Jorge Alberto Villwock, um dos pioneiros nos estudos costeiros e marinhos no Brasil. Agradecemos ao Porto de Rio Grande (SUPRG) pela contribuição ao longo desta pesquisa.

\section{Referências}

Almeida, S.R. 2004. Subsídios para o gerenciamento ambiental de projetos de dragagem em portos. Rio de Janeiro, 190p. Dissertação de Mestrado, Instituto Militar de Engenharia, Programa de Pós-graduação em Engenharia de Transportes, Exército Brasileiro. Antiqueira, L. N. 2018. Estudo do processo erosivo e proposta de engenharia para fixação das margens - Ilha do Terrapleno de Leste. Rio Grande, 131p. Monografia de Conclusão de Curso, Curso de Engenharia Civil Costeira e Portuária, Escola de Engenharia, Universidade Federal de Rio Grande.

Asmus, M.L. 2006. Programa de monitoramento ambiental para o canal de acesso ao Porto de Rio Grande, bacia de evolução do Porto novo e da área de descarte do material dragado. Rio Grande. Superintendência do Porto de Rio Grande. Relatório anual, 1 CD-ROM.

Burgueño, L.E.T. 2009. Estimativas da contaminação dos sedimentos dragados no porto de Rio Grande para disposição em solo. Rio Grande, 165p. Dissertação de Mestrado, Programa de Pós-graduação em Engenharia Oceânica, Universidade Federal de Rio Grande.

Calliari, L.J., Speranski, N.S., Torronteguy, M. \& Oliveira, M.B. 2000. The mud banks of Cassino beach, southern Brazil: Characteristics, Processes and Effects. Journal of Coastal Research, 24(1): 318-325.

Calliari, L.J., Cunha,R.P. \& Antiqueira, J. A. F. 2010. Geomorfologia e dinâmica sedimentar. In: Seeliger, U, Odebrecht, C. (Ed.). O estuário da Lagoa dos Patos: Um século de transformações. $1^{\text {a }}$. ed. Rio Grande: Editora da FURG, p. 31-39.

Calliari, L.J., Machado, A.A., Marroig, P., Vinzon, S. \& Gianuca, N. 2016. Mud deposits at Cassino beach: natural versus antrophic. In: INTERNATIONAL CONFERENCE ON COASTAL AND PORT ENGINEERING IN DEVELOPING
COUNTRIES - IX PIANC-COPEDEC, 2016, Rio de Janeiro, v. 1, 86-87.

Calliari, L.J., Machado, A.A., Marroig, P., Vinzon, S. \& Gianuca, N. 2020. Mud deposits at Cassino beach: role of dredging. Geo-Marine Letters, 40: $1031-1043$.

Castelão, R.M \& Möller, O.O. 2003. Sobre a circulação tridimensional forçada por ventos na Lagoa dos Patos. Atlântica, 25(2): 91-106.

Castiglia, M.C.C.P. 2006. Disposição subaquática de rejeitos de dragagem: o caso do complexo lagunar de Jacarepaguá. RJ. Rio de Janeiro. 170p. Dissertação de Mestrado, Programa de Pós-graduação em Engenharia Civil, Universidade Federal do Rio de Janeiro.

Castiglia, M.C.C.P. 2008. Análise Geotécnica e Hidrodinâmica da Alternativa de Disposição Subaquática dos Rejeitos de Dragagem do Complexo Lagunar de Jacarepaguá - Rio de Janeiro. In: XIV CONGRESSO BRASILEIRO DE MECÂNICA DOS SOLOS E ENGENHARIA GEOTÉCNICA, Búzios, RJ, v. 1, 1065-1072.

Castro, S.M. \& Almeida, J.R. 2012. Dragagem e conflitos ambientais em portos clássicos e modernos: uma revisão. Sociedade \& Natureza, 24(3): 519-533.

Choueri, R.B, Cesar, A., Abessa, D.M.S., Torres, R.J., Morais, R.D., Riba, I., Pereira, C.D.S., Nascimento, M.R.L., Mozeto, A.A. \& DelValls, T.A. 2009. Development of site-specific sediment quality guidelines for North and South Atlantic littoral zones: Comparison against national and international sediment quality benchmarks. Journal of Hazardous Materials, 170(1): 320-331.

CONAMA. Conselho Nacional de Meio Ambiente. 2012. Resolução 454. Brasília, DF.

Costa, P.A, 2002. Itha do Terrapleno de Leste: De pântano salgado á base aeronaval. Rio Grande, 84p. Monografia de Conclusão de Curso de Geografia, Universidade Federal de Rio Grande.

Crowell, M., Leikin, H. \& Buckley, M.K. 1999. Evaluation of coastal erosion hazards study: an overview. Journal of Coastal Research, 28(SI): 2-9.

Delaney, P. 1965. Fisiografia e geologia de superfície da planície costeira do Rio Grande do Sul. Publicação Especial da Escola de 
Geologia de Porto Alegre, 6: 1-105.

DEPREC. Departamento Nacional de Portos e Navegação. 1939. Relatório Rio Grande, 1939. Datilografado. Acervo DEPREC.

DOCM. Diretoria de Obras Civis da Marinha. 2014. Folha militar online. Disponível em: <http:// folhamilitaronline.com.br>. Acesso em 02 mai. 2020.

Dumith, R.C., Telles, R.M. \& Lucas, L.M. 2008. Modificações geomorfológicas do sítio urbano do Rio Grande (RS), a partir da intensificação do uso e ocupação do solo. Geografia. Ensino \& Pesquisa, 12(1): 2834-2849.

Felgueiras, C.A., Druck, S. \& Monteiro, A.M.V. 2002. Análise espacial de superfícies: o enfoque da geoestatistíca por indicação. In: Druck, S, Carvalho, M.S., Câmara, G., Monteiro, A.M.V. (Ed.). Análise espacial de dados geográficos. São José dos Campos: INPE, p. 25-50.

Folk, R.L. \& Ward, W.C. 1957. Brazos River bar [Texas]; a study in the significance of grain size parameters. Journal of Sedimentary Research, 27(1): 3-26.

Garcia, F.A.P., Baisch, P.R., Mirlean, N. \& Griep, G.H. 2008. Subsídios legais e aspectos técnicos para monitoramento geoquímico de sedimentos. In: Boldrine, E.B., Soares, C.R., Paula, E.V. (Ed.). Dragagens Portuárias no Brasil Engenharia, Tecnologia e Meio Ambiente. ed. Antonina, v. 1, p. 136-142.

Goes Filho, H.A. 1979. Planejamento de Dragagem. Boletim Técnico da Associação Latino-Americana de Dragagem, 2(1): 9-20.

Goes Filho, H.A. 2004. Dragagem e gestão dos sedimentos. Rio de Janeiro, 162p. Dissertação de Mestrado, Programa de Pós-graduação de Engenharia, Universidade Federal do Rio de Janeiro.

Granato, F.C. 2005. Subsídios técnicos para o estabelecimento de um plano de gerenciamento ambiental integrado do processo de dragagem do porto de Rio Grande - RS. Rio Grande, 138p. Dissertação de Mestrado, Programa de Pós-graduação em Oceanografia Física, Química e Geológica, Universidade Federal do Rio Grande.

Hermanns, L. 2017. Estratégias ambientais para utilização de material de dragagem. Porto Alegre, 88p. Tese de Doutorado, Programa de
Pós-graduação em Geociências., Universidade Federal do Rio Grande do Sul.

Herz, R. 1977. Circulação das águas de superfície da Lagoa dos Patos. São Paulo, 722p. Tese de Doutorado, Faculdade de Filosofia Letras e Ciências Humanas, Departamento de Geografia. Universidade de São Paulo.

Hinchee, R.E., Porta, A., \& Pellei, M. 2002. Remediation and Beneficial Reuse of Contaminated Sediments. Venice, Battelle Press, 463p.

IFPRC. Inspetoria Federal de Portos, Rios e Canais. 1926. Coletânea de leis, documentos e demais atos oficiais relativos ao Porto do Rio Grande do Sul, concedido ao Estado do Rio Grande do Sul. Vol. II, Rio de Janeiro, 235p. Kitzmann, D. \& Asmus, M.L. 2006. Gestão ambiental portuária: Desafios e possibilidades. Revista Brasileira de Administração Pública, 40(1): 1041-1060.

Lacey, H. 2006. O princípio de precaução e a autonomia da ciência. Scientiae Studia, 4(3): 373-392.

Leatherman, S.P., Zhang, K. \& Douglas, B.C. 2000. Sea level rise show to drive coastal erosion. Eos, Transactions American Geophysical Union, 81(6): 55-57.

Lima, L.R.S. 2008. Dragagem, transporte e disposição final de sedimentos de leito de rio. Estudo de caso: Calha do Rio Tietê. São Paulo, 145p. Dissertação de Mestrado, Programa de Pós-graduação em Engenharia, Escola Politécnica, Universidade de São Paulo.

Manap, N. \& Voulvoulis, N. 2015. Environmental management for dredging sediments - The requirement of developing nations. Journal of Environmental Management, 147, 338-348.

IBGE. Instituto Brasileiro de Geografia e Estatística. 2004. Vocabulário básico de recursos minerais e meio ambiente. 2a. ed., Rio de Janeiro, IBGE, 332p.

Marinha do Brasil, 2014. Relatório da erosão no parque de antenas da PMO. Estação Radiogoniométrica da Marinha no Rio Grande. Divisão de serviços especiais. Rio Grande, $15 p$.

Mirlean, N., Calliari, L.J. \& Johannesson, K. 2020. Dredging in an estuary causes contamination by fluid mud on a tourist ocean beach. Evidence 
via REE ratios. Marine Pollution Bulletin, 159: 11495.

Monteiro, M.T. 2008. Fitorremediação de rejeito contaminado proveniente do Canal do Fundão, na Baía de Guanabara-RJ. Rio de Janeiro, 340p. Tese de Doutorado, Programa de Pósgraduação em Engenharia Civil, Universidade Federal do Rio de Janeiro.

MRS. MRS Estudos Ambientais Ltda. 2007. Estudo de Impacto Ambiental (EIA) e Relatório de Impacto Ambiental (Rima). Ampliação dos Molhes e Dragagem de Aprofundamento do Canal de Acesso no Porto do Rio Grande no Estado do Rio Grande do Sul. Porto Alegre, $128 p$.

Neu, M.F.R. 2011. Relação porto e cidade: breve estudo comparativo entre Paranaguá (PR) e Rio Grande (RS). Cadernos do Núcleo de Análises Urbanas, 5(1). Disponível em https:// periodicos.furg.br/cnau/article/view/4754. Acesso em 15 nov. 2020.

Nicolodi, J.L., Toldo Jr., E.E. \& Farina, L. 2010. Dinâmica e ressuspensão por ondas no Lago Guaíba (RS, Brasil) e implicações nos locais de captação de água para abastecimento humano. Pesquisas em Geociências, 37: 2539.

PIANC. International Navigation Association 1992. Beneficial Uses of Dredged Material. Brussels, EnviCom Working Group 104, 175p.

POYRY. Tecnologia Ltda. Estudo de Impacto Ambiental (EIA) e Relatório de Impacto Ambiental (Rima). 2008. Dragagem de aprofundamento dos canais de acesso ao Porto Novo, Porto de São José do Norte e suas bacias de evolução. Rio Grande do Sul, 80p.

Santos, I.R., Baisch, P., Lima, G.; Mirlean, N., Griep, G. \& Silva Filho, E.V. 2004. Análise Estatística Multivariada de Parâmetros Geoquímicos em Sedimentos do Estuário da Lagoa dos Patos. Geochimica Brasiliensis, 18(1): 38-45.

Seeliger, U. \& Costa, C.S.B. 1998. Impactos naturais e humanos. In: Seeliger, U, Odebrecht, C. \& Castello, J.P. (Eds.). Os Ecossistemas Costeiro e Marinho do Extremo Sul do Brasil. Editora Ecoscientia. Rio Grande, p. 219-226.

Seeliger, U. \& Costa, C.S.B. 2002. The Patos-Mirin basins, lagoons and estuary, South Brazil: Natural and human forcing factors. In: Lacerda,
L.D., Kremer, H.H., Kjerfve,B., Salomons, W., Marshall, J.I. (eds.). South American Basins: LOICZ Global Change Assessment and Synthesis of River Catchment-Coastal Sea Interaction and Human Dimensions. LOICZ Reports \& Studies. The Netherlands, 21, p. 105-112.

Shepard, F.P. 1954. Nomenclature based on sand-silt-clay ratios. Journal of sedimentary Research, 24(3): 151-158.

Silva, M.J.B, 2019. Estudo dos processos de sedimentação no porto de Rio Grande (Brasil). Rio Grande, 179p. Dissertação de Mestrado, Programa de Pós-graduação em Engenharia Oceânica, Universidade Federal do Rio Grande.

Suguio, K. Introdução à sedimentologia. São Paulo, Ed. Edgard Blucher Ltda./Edusp, 317p. SUPRG. Superintendência do Porto de Rio Grande. 2019. Plano de desenvolvimento e zoneamento do Porto de Rio Grande. Rio Grande, RS. 574p.

Teixeira, L.S \& Dias, C.R, 2011. Estudo das propriedades químicas dos rejeitos de dragagem para utilização como solo fabricado para fins agrícolas. In: SEMINÁRIO E WORKSHOP EM ENGENHARIA OCEÂNICA. 2011. Rio Grande. Anais. V.1.

Telles, R.M. 2011. A evolução geomorfológica de Rio Grande: um Contraste de dois tempos. Cadernos do Núcleo de Análises Urbanas, 5(1), 20p.

Thieler, E.R., Himmelstoss, E.A., Zichichi, J.L. \& Ergul, A. 2009. Digital Shoreline Analysis System (DSAS) version 4.0- An ArcGIS extension for calculating shoreline change: U.S. Geological Survey Open-File Report.

Toldo Jr., E.E. \& Almeida, L.E.S.B., 2003. A Linha de Água como Indicadora da Posição da Linha de Praia. In: Proceedings of the IX Congresso da Associação Brasileira de Estudos do Quaternário, Recife, PE, v. 19. Disponível em http://www.abequa.org.br/trabalhos/ quatcost_88.pdf. Consultado em 01 out. 2020.

Tomazelli, L.J. \& Villwock, J.A. 1996. Quaternary Geological Evolution of Rio Grande do Sul Coastal Plain, Southern Brazil. Anais da Academia Brasileira de Ciências, 68: 373-382.

Torres, R.J. 2000. Uma Análise Preliminar dos Processos de Dragagem do Porto de Rio 
Grande, RS. Rio Grande, 190p. Dissertação de Mestrado, Programa de Pós-graduação em Engenharia Oceânica, Universidade Federal de Rio Grande.

Torres, R.J., Abessa, D.M.S., Santos, F.C., Maranho, L.A., Davanso, M. B., Nascimento, M.R.L. \& Mozeto, A.A. 2009. Effects of dredging operations on sediment quality: contaminant mobilization in dredged sediments from the Port of Santos, SP, Brazil. Soils and Sediment Contamination, 9: 420-432.

USACE. US Army Corps OF Engineers. 1987. Engineering and Design - Beneficial Uses of Dredged Material, Engineer Manual 1110-25026, Washington, DC, $178 \mathrm{p}$.

Vellinga, T. 1998. Guide de gestion des matériaux de dragage: rapport spécial de la Commissionsuple Permanente de I'Environnement. International Navigation Association. Paris, 82p.

Vellinga T. \& Eisma M. 2005. Management of contaminated dredged material in the port of Rotterdam. In: Vermaat J., Salomons W., Bouwer L., Turner K. (Eds). Managing European Coasts. Environmental Science. Springer, Berlin, p. 315-322.

Vieira, E.F. 2014. Dialética do acontecimento sedimentar no litoral do Rio Grande do Sul. Revista do Instituto Histórico e Geográfico do $R S$, 148(1): 31-43.

Villwock, J.A. \& Tomazelli, L.J. 1995. Geologia Costeira do Rio Grande do Sul. Notas Técnicas CECO, 8:1-45.

Villwock, B.J. 2019. Potencialidade de utilização da ilha do terrapleno para a deposição de sedimentos dragados do porto de Rio Grande, RS. Rio Grande, 123p. Dissertação de Mestrado, Programa de Pós-graduação em Gerenciamento Costeiro, Instituto de Oceanografia, Universidade Federal de Rio
Grande.

Volpato, S.B., de Menezes, C.T.B., \& da Silva, J.V.F. 2017. Recuperaçãoambiental deecossistemas aquáticos em regiões estuarinas: estudos aplicados para o tratamento de sedimentos contaminados pela drenagem ácida de mina na Bacia Hidrográfica do Rio Urussanga, Santa Catarina. Revista Engenharia Sanitária, 22: 313-316.

Manuscrito 106479 | Recebido em ago. de 2020 | Aceito em jul. de 2021 | Editora: Nina S. V. Moura 